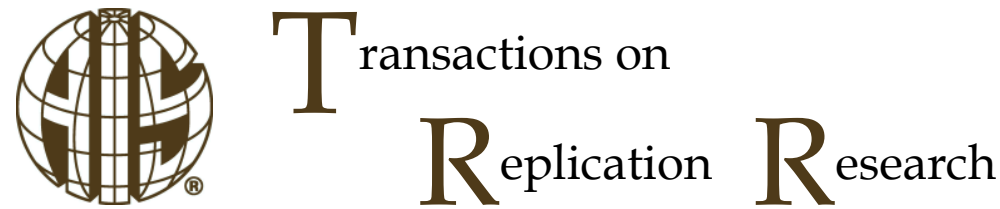

Methodological Replication

ISSN 2473-3458

\section{Shackled to the Status Quo: A Replication}

\author{
Binny M. Samuel \\ University of Cincinnati \\ samuelby@uc.edu
}

\author{
George K. Joy \\ Deloitte Consulting \\ georkizh@umail.iu.edu
}

\begin{abstract}
:
We conducted a methodological replication of the Polites and Karahanna (2012) model of incumbent system influence on switching to a new Information System using e-mail systems Gmail and Inbox as the incumbent and new systems, respectively. Our replication results support much of the original study. Inertia to use the existing system significantly affected intentions to use the new system. Inertia also affected perceptions of the new system (perceived ease of use and relative advantage) which in turn affected intentions. We found a few differences from the original study and highlight what we consider the major ones. First, the original study found that sunk costs, incumbent system habit, and transition costs all significantly influenced inertia, whereas we found that only sunk costs had a significant influence on inertia. We attribute this to the differences in technologies studied; the original study examined a technology that required a change in both software and work processes whereas we studied a technology switch that only required a change in software (no major change in work processes). Second, the original study found a complex two-part moderation of inertia on the relationship between subjective norm and intentions, while we found a simple direct effect of subjective norm on intentions with no moderation. We also attribute this to the differences in technologies studied; the original study examined a technology that required mutual switch by two parties whereas we studied a technology that required a switch by only one.
\end{abstract}

Keywords: methodological replication, technology switching, status quo bias

The manuscript was received 03/18/2016 and was with the authors 11 months for two revisions. 


\section{Introduction}

The adoption and use of information systems is an important, long-standing, and active area of research (Benbasat \& Barki, 2007; V. Venkatesh \& Thong, 2012). Many studies have examined the initial information system adoption using models such as the Technology Acceptance Model (TAM) (Davis, 1989; Davis, Bagozzi, \& Warshaw, 1989) and the Unified Theory of Acceptance and Use of Technology (UTAUT) (V. Venkatesh, Morris, Davis, \& Davis, 2003). These models have become rather complex over time as new factors were added (Straub \& Burton-Jones, 2007).

In many cases, the new system replaces an existing system, so it is important to consider the existing system and the habits that have built up around its use (Polites \& Karahanna, 2012). Thus rather than simply being better than the existing system, the new system must be sufficiently better to overcome the habitual use of the existing system and the switching costs incurred in moving to the new system (Polites \& Karahanna, 2012). In other words, long term use of the existing system has created inertia that, ceteris paribus, will lead to resistance to change (Polites \& Karahanna, 2012).

Research by Polites and Karahanna (2012) brought the more encompassing perspective of technology switching to the IS literature and found a status quo bias; inertia from the existing system for sharing files (e-mail) significantly influenced the adoption of the new system (Google Docs). Figure 1 presents their results. They found that the incumbent system habit, sunk costs and transition costs led to inertia, and inertia had a direct effect on intentions to use the new system. Perhaps more interestingly, inertia influenced perceptions of the ease of use and advantages of the new system, and also interacted with subjective norm to influence intentions.

In this paper we present a methodological replication of the study by Polites and Karahanna (2012). We used the same methods as they did, and studied a similar population (US business school undergraduates) but examined a different technology: switching between two e-mail systems, from Google Gmail to Google Inbox.

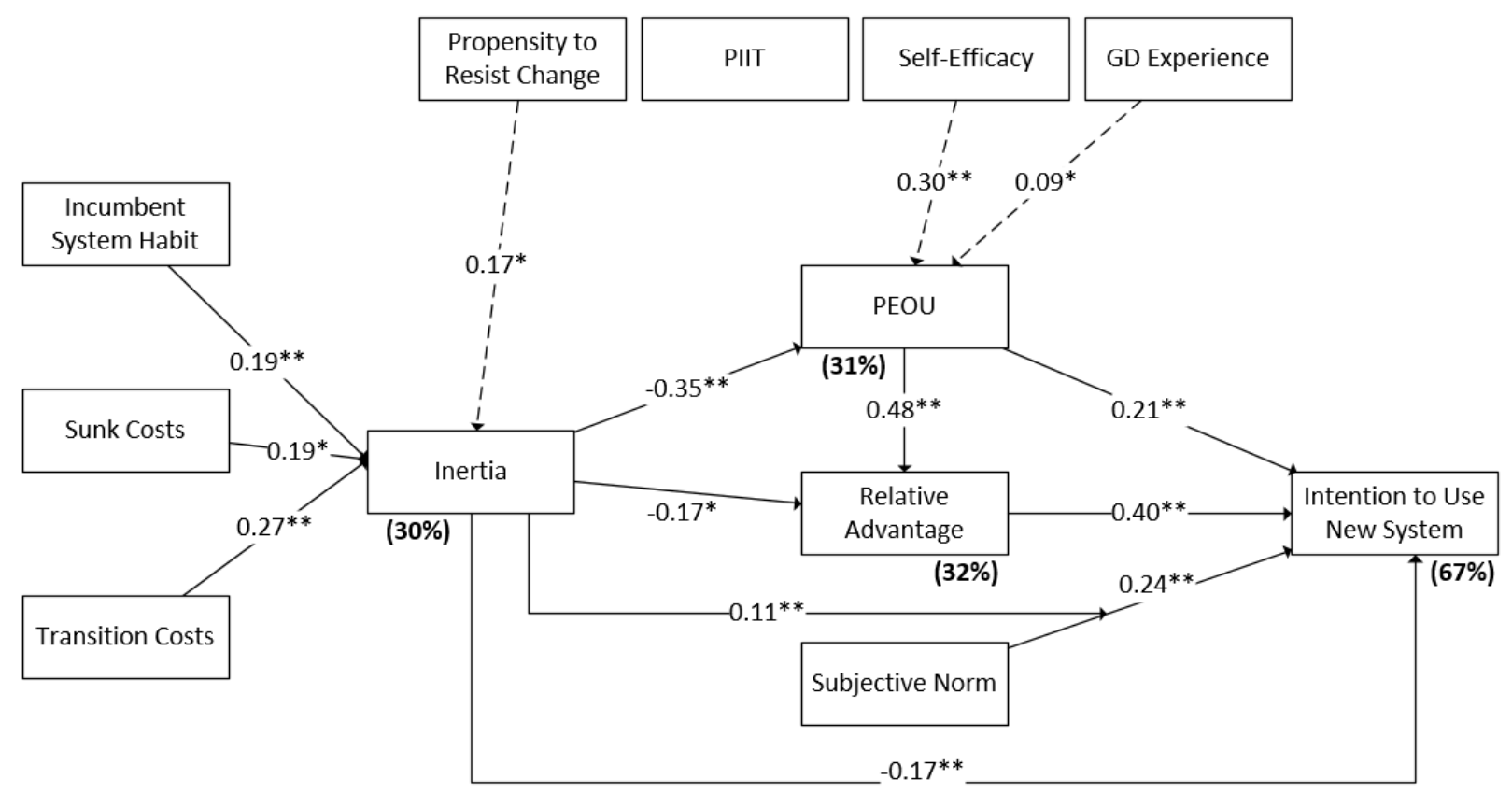

Note: Dotted lines represent control variable significant effect (nonsignificant effects of control variables are not shown). Terms in parentheses represent the percentage of explained variance.

$* \mathrm{p}<0.01 \quad * * \mathrm{p}<0.001$

Figure 1. Results from Polites and Karahanna (2012) 


\section{Methodology}

We followed the same two-part methodology as Polites and Karahanna (2012). The first part was an online survey about the existing e-mail system, Google Gmail (Gmail). Gmail is the official university e-mail system $^{1}$, so all participants have used it. The second part involved participants attending a lab session where they interacted with new e-mail system Google Inbox (Inbox) and then completed a second survey.

\subsection{Participants}

We recruited participants who were undergraduate students at a large US state university and enrolled in a required third year business course. 292 participants completed the first survey, 203 completed the second survey, and 196 completed both surveys and were subsequently included in the analysis.

\subsection{Tasks}

We used the same approach to the task as Polites and Karahanna (2012), but adapted it to our system. Participants first watched a video produced by Google designed to introduce potential users to Inbox. We highlight the key differences of Inbox compared to Gmail, both of which are Google products. Inbox is an email system designed for individuals with limited time to read through e-mails. Inbox includes features that Gmail does not, some of which rely on machine learning $2: 1)$ bundling messages from different senders by content e.g., Purchases; 2) displaying highlights of key message content without having to open the message e.g., shipping status of an order; 3) the ability to create reminders in your e-mail system; 4) snoozing messages or reminders to allow you to focus on other tasks; and 5) offering automatic smart replies to messages. After watching the video participants used Inbox to perform a few tasks using mock email accounts created for this study. Appendix A8 provides the task instructions given to participants.

\subsection{Measures}

We used the same measures as Polites and Karahanna (2012). We retained the same construct and item labels as Polites and Karahanna (2012) to make comparisons between studies easier, but modified the content of the measures as needed for our context of e-mail systems. Appendix A5 provides the items ${ }^{3}$.

\section{Data Analysis and Results}

\subsection{Measurement Model}

We used SmartPLS 3.2.3 (Ringle, Wende, \& Becker, 2015) to analyze both the measurement model and structural model. Habit, inertia, and propensity to resist change were modeled as second-order formative, first-order reflective multidimensional constructs. In assessing the measurement model, we replicated the work of Polites and Karahanna (2012) and first started with assessing the first-order reflective scales following the guidelines of Fornell and Larcker (1981). We found a multidimensional structure for habit, inertia, and propensity to resist change.

We assessed the reliability, discriminant validity, and convergent validity of the first order measurement model. The composite reliabilities (please see Appendix A1) of the first order constructs ranged from 0.82 up to 0.97 and exceeded the threshold of 0.70 . We assessed discriminant validity with two steps. First, all items loaded significantly on their construct of interest above the recommended threshold of 0.70 with low cross-loadings on other items (see Appendix A2). Second, we assessed the square root of the average variance extracted (AVE) of each construct compared to its correlations with other constructs. The square root of each construct's AVE was greater than its correlations with other constructs in the model (please see Appendix A1). Last, we assessed the convergent validity by ensuring that AVE exceeded 0.50 for each construct.

${ }_{1}^{1}$ The incumbent e-mail system was essentially Gmail, but it was branded as Umail at the university.

2 For more details, please see: 1) https://www.google.com/inbox/ 2) http://www.pcworld.com/article/2935949/ and 3) https://www.wired.com/2016/03/google-inbox-auto-answers-e-mails/

${ }^{3}$ The construct and item labels from the original study were retained in the appendix to allow readers to map them between this replication study and the original study. The item wordings were adapted for the context of this study. 
We also assessed potential common method bias issues using techniques conducted by Polites and Karahanna (2012) drawing from Podsakoff, MacKenzie, Lee, and Podsakoff (2003). First, we separated the time of the first part of the study (i.e., survey regarding the incumbent system) and the second part of the study (i.e., lab session with the new system). We had on average a two-week temporal separation of the data collection between the first and second parts of the study. Second, we conducted a Harman's singlefactor test and more than one factor emerged to determine the number of factors necessary to account for the variance in the variables with the highest variance of any one factor being $16 \%$. Third, we utilized a common method factor following the practice of Liang, Saraf, Hu, and Xue (2007) and found that the method factor loadings were insignificant and had variances that were substantially less than the substantive variance; averages of 0.001 and 0.83 respectively. Collectively, our steps to alleviate and test for common method bias suggest that it is unlikely to be a major concern. Given these results, the constructs satisfactorily passed tests to assess their psychometric properties.

\subsection{Structural Model}

Before proceeding to assess the structural paths in the model, we first assessed the second-order aggregate constructs (i.e., habit, inertia, and propensity to resist change). This was consistent with the work of Polites and Karahanna (2012). We relied on the factor scores generated from the first order measurement model evaluation to create formative measures of the second-order aggregate constructs. Habit consisted of the following first-order constructs: Awareness, Control, and Mental Efficiency. Inertia consisted of: Affective Based, Behavioral Based, and Cognitive Based inertias. Last, Propensity to Resist Change consisted of Cognitive Rigidity, Emotional Reaction, Routine Seeking, and Short-Term Focus. We note that Subjective Norm was modeled as a first-order formative construct and also discuss its evaluation in this section.

To assess for multicollinearity issues with the formative constructs, we examined their Variance Inflation Factor (VIF) values. All three Subjective Norm (SN) items were above the VIF threshold of 3.3 suggested by Petter, Straub, and Rai (2007); GDSF1: 9.4; GDSF3: 11.8; GDSF5: 3.6. Prescriptions to remediate multicollinearity suggest dropping one of the three items i.e., starting with GDSF3 given the highest VIF. However, all three items are essential facets of SN used in prior research, and therefore it did not seem appropriate to remove any of them from the model from a content validity perspective. Thus, instead we summed each of the three dimensions of SN and created a composite index (see Petter et al., 2007 and Cenfetelli \& Bassellier, 2009). All of the second-order formative constructs were below the suggested 3.3 VIF threshold. The Habit dimensions ranged from 1.7 to 2.0, the Inertia dimensions ranged from 1.2 to 1.6, and the Propensity to Resist Change dimensions ranged from 1.1 to 1.4.

Polites and Karahanna (2012) also assessed the partial correlations within the dimensions of the secondorder formative construct Habit to ensure there were no suppressor variables effects. They found an issue with the Habit construct and its Awareness dimension. We also found evidence to suggest that Awareness might confound (Friedman \& Wall, 2005) the other dimensions of Habit. Specifically, the bivariate correlation between Awareness and Habit was 0.92, the bivariate correlation between Control and Habit was 0.36, and the bivariate correlation between Mental Efficiency and Habit was 0.30 . However, the partial correlation of Control with Habit after controlling for Awareness was -0.71 and the partial correlation Mental Efficiency with Habit after controlling for Awareness was -0.86. Since all three dimensions of Habit were theory-derived facets, it is not appropriate to remove any of them without damaging content validity (Petter et al., 2007), so we created a single composite index for Habit using the factor scores of its dimensions. This was in line with what Polites and Karahanna (2012) did as well. Prior to this single composite index the weights were: Awareness $=1.30$, Control $=-0.26$, Mental Efficiency $=-0.34$.

Appendix A3 contains the weights of the PLS structural model using the summed Habit score and Subjective Norm score. We note that only the Affective Based dimension of Inertia was significant, however given concerns for affecting the content validity of the Inertia construct we retained the Cognitive Based and Behavioral Based dimensions of the construct. Each of the bivariate correlations of the Inertia dimensions were significant, and rerunning the model after dropping the non-significant dimensions yielded similar results when all dimensions were present. We present the inter-construct correlations for the final PLS structural model in Appendix A4. 
Figure 2 shows the results of the structural model with the significant paths noted. Starting from the left of Figure 2, only Sunk Costs was significant in predicting Inertia with a positive relationship of $0.32^{4}$. Inertia had significant negative path coefficients in predicting Perceived Ease of Use (PEOU), Relative Advantage (RA), and Intentions to Use the New System (Intention). PEOU, RA, and SN had significant paths in the direction predicted by theory. Last, Self-Efficacy and Experience with the new system were the only two control variables with a significant path. The $\mathrm{R}^{2}$ of the endogenous latent variables was $23 \%$ for Inertia, $23 \%$ for PEOU, $28 \%$ for RA, and $56 \%$ for Intention. The effect size of Inertia on Intention, RA, and PEOU is $0.22,0.09$, and 0.09 respectively, the first of which is medium and the latter two are small effect sizes. Although the effect size of Inertia on Intention is only moderate, its total effect is large (see Appendix A6) and greater than PEOU and RA. Similarly, the total effect of Inertia on PEOU and RA are moderately large despite the weak effect size.

To assess the mediation relationships in the model, we followed the guidelines of Hair, Hult, Ringle, and Sarstedt (2014) [see Exhibit 7.18 on p.224] which operationalize the recommendations of Preacher and Hayes (2008) to PLS-SEM for assessing mediation. The detailed results of our analysis is in Appendix A7. Our results indicate that Inertia 1) does not mediate the effects of Habit on the TAM constructs; 2) partially mediates the effect of Sunk Costs on PEOU; 3) fully mediates the effects of Sunk Costs on Intentions; and 4) partially mediates the effects of Transition Costs on RA and Intentions. Consistent with the original study, we also found that RA mediates the effect of PEOU on Intentions. Last, given Polites and Karahanna (2012) debate between SN as a mediator or moderator of the effect of Inertia on Intentions, we found no evidence of SN as a mediator. We summarize our overall results compared to that of Polites and Karahanna (2012) in Table 1. We indicate where there was Full, Partial, and No support for the hypothesized relationships across the studies. $\mathrm{H} 4$ has several components to it, and we present an overall similarity to the original study as well as the detailed comparisons.

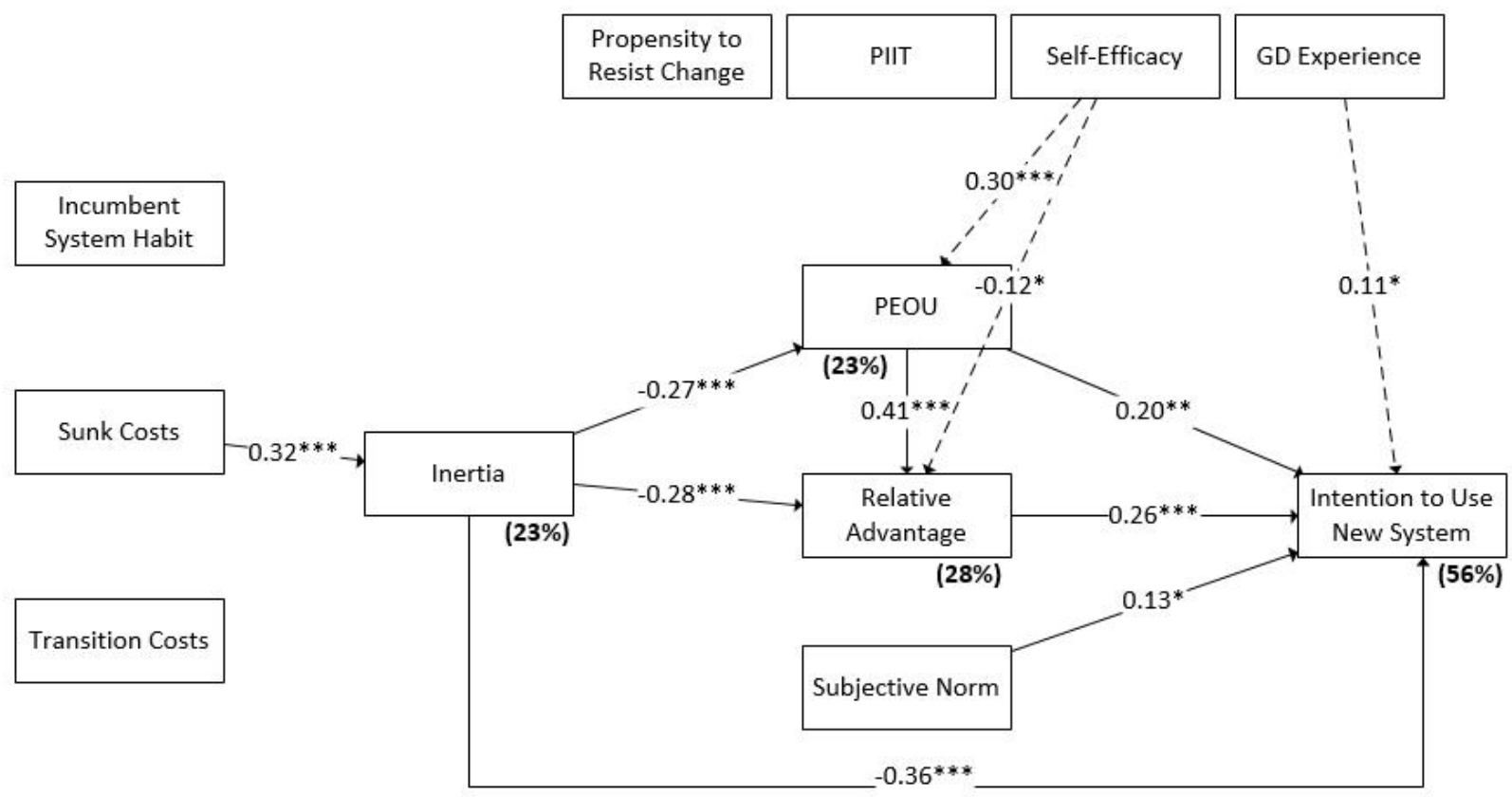

Note: Dotted lines represent control variable significant effect (nonsignificant effects of control variables are not shown). Terms in parentheses represent the percentage of explained variance.

$* \mathrm{p}<0.05 * * \mathrm{p}<0.01 * * * \mathrm{p}<0.001$

Figure 2. Results from this paper

${ }^{4}$ Path coefficient from Incumbent System Habit to Inertia was 0.11 , and -0.13 from Transition Costs to Inertia. 


\section{Discussion}

\subsection{Discussion of Findings}

In this section, we summarize the findings of our replication. We start by presenting the consistent findings with the original study and then comment on the differences. We refer to the hypotheses in Table 1 to guide the reader through the discussion.

First, we found that Sunk Costs significantly and positively impacted Inertia (see H3 in Table 1). Next, Inertia in the existing system affected perceptions of the new system (perceived ease of use, $\mathrm{H} 5$, and relative advantage, H6). These two attitudinal beliefs had a positive impact on intentions to use the new system. Inertia due to the existing system also significantly and directly affected intentions to use the new system $(\mathrm{H} 7)$. Last, similar to the original study, we found partial support that Inertia would fully mediate the relationships between the incumbent system constructs and the new system acceptance constructs $(\mathrm{H} 4)$. There were differences in the consistency of our findings regarding the specific mediation paths of the original study in $\mathrm{H} 4$ (see Table 2), and we discuss those later. Overall, given that five of the eight original study hypotheses were supported in this replication, we conclude that the theory and constructs developed in the original study generalize well into the context we studied.

Table 1. Support for Hypotheses from the Original Study to Replication Study

\begin{tabular}{|l|c|c|}
\hline $\begin{array}{c}\text { Hypothesized Relationship } \\
\text { (from Polites and Karahanna) }\end{array}$ & Findings of Polites and Karahanna (2012) & Replication Findings \\
\hline $\begin{array}{l}\text { H1: Incumbent System Habit will } \\
\text { positively impact Inertia }\end{array}$ & Full* & No \\
\hline $\begin{array}{l}\text { H2: Transition Costs will positively } \\
\text { impact Inertia }\end{array}$ & Full & Full \\
\hline $\begin{array}{l}\text { H3: Sunk Costs will positively } \\
\text { impact Inertia }\end{array}$ & Full \\
\hline $\begin{array}{l}\text { H4: Inertia fully mediates the } \\
\text { relationships between the } \\
\text { incumbent system constructs (i.e., } \\
\text { habit, transition costs, and sunk } \\
\text { costs) and the new system } \\
\text { acceptance constructs (i.e., Ease } \\
\text { of Use, Relative Advantage, and } \\
\text { Intention to Use New System) }\end{array}$ & Partial (details in Table 2 below) & Partial (details in Table 2 below) \\
\hline $\begin{array}{l}\text { H5: Inertia will negatively impact } \\
\text { New System Ease of Use }\end{array}$ & Full & Full \\
\hline $\begin{array}{l}\text { H6: Inertia will negatively impact } \\
\text { New System Relative Advantage }\end{array}$ & Full & Full \\
\hline $\begin{array}{l}\text { H7: Inertia will negatively impact } \\
\text { Intention to Use New System }\end{array}$ & Full & Full \\
\hline $\begin{array}{l}\text { H8: Inertia will moderate the } \\
\text { relationship between subjective } \\
\text { norm and intentions to use the } \\
\text { new system; high inertia will } \\
\text { strengthen the positive relationship } \\
\text { between subjective norm and } \\
\text { intensions to use the new system }\end{array}$ & & Full \\
\hline *A designation of Full, Partial, or No is used to indicate the degree of support for the original hypotheses proposed. \\
\hline
\end{tabular}


Table 2. Details of Hypothesis Four from the Original Study to Replication Study

\begin{tabular}{|c|c|c|c|c|c|c|c|}
\hline \multicolumn{4}{|c|}{ Findings of Polites and Karahanna (2012) } & \multicolumn{4}{|c|}{ Replication Findings } \\
\hline $\mathrm{IV} \quad \mathrm{DV}$ & Ease of Use & $\begin{array}{c}\text { Relative } \\
\text { Advantage }\end{array}$ & $\begin{array}{c}\text { Intention to } \\
\text { Use }\end{array}$ & $\mathrm{IV} D \mathrm{DV}$ & Ease of Use & $\begin{array}{c}\text { Relative } \\
\text { Advantage }\end{array}$ & $\begin{array}{c}\text { Intention to } \\
\text { Use }\end{array}$ \\
\hline Habit & Full $^{\star}$ & Full & Full & Habit & No & No & No \\
\hline $\begin{array}{l}\text { Transition } \\
\text { Costs }\end{array}$ & No & No & Full & $\begin{array}{l}\text { Transition } \\
\text { Costs }\end{array}$ & No & Partial & Partial \\
\hline Sunk Costs & Full & Full & Full & Sunk Costs & Partial & No & Full \\
\hline
\end{tabular}

There were a few differences in findings between our replication and the original study. First, the original study found that incumbent system habit and transition costs also significantly influenced inertia (see $\mathrm{H} 1$ and $\mathrm{H}_{2}$ ) and together accounted for $30 \%$ of its variance. In contrast, we found that only sunk costs had a significant influence on inertia. We account for this difference due to the nature of the existing and new systems. Specifically, we speculate there is a difference between using a new system with similar work processes vs. using a new system with different work processes. Polites and Karahanna (2012) studied technology switching from file sharing via e-mail to file sharing using Google Docs, whereas we studied the switch between two e-mail systems from the same provider (Google Gmail and Google Inbox). In our case, it was a switch in software (one e-mail system for another), however the participants in the Polites and Karahanna (2012) study encountered a fundamental change in work processes as well as software (i.e., a change from e-mail attachments to a file-sharing repository). The shift for the Polites and Karahanna (2012) participants was much larger; they were being asked about switching from a system they used frequently (e-mail) to a new system requiring a different work process by uploading and working on files on a server where teams had additional features available to them. Our replication context may not have provided a suitable enough hurdle of change (i.e., that is a system change that also required a work process change) to observe similar results as the original study regarding habit and transition costs significantly influencing inertia.

Therefore, when considering switching to a new system that requires a major change in work process as well as software change, users consider factors such as sunk costs, incumbent system habits, and transition costs. Whereas, when asked about switching to a new system that enables the use of the same work processes, users focus only on the sunk costs they invested in learning how to use the existing software; habits and transition costs are less important because they are more strongly influenced by the work processes, not the software.

Although not a formal hypothesis in Table 1, we also note that the original study found that two of the three dimensions of Inertia (a second-order formative construct) were significant. Polites and Karahanna (2012) found that the Affective-Based and Cognitive-Based dimensions were significant. We only found that the Affective-Based dimension was significant in our replication and did not find support that the CognitiveBased dimension was significant. The Cognitive-Based dimension emphasized knowledge that the incumbent system was 1) not the best way; 2) not the most efficient way; and 3) not the most effective way to accomplish tasks. In our context although Inbox offered a better alternative to Gmail (the incumbent), the lab setting may not have provided sufficient time for our subjects to cognitively internalize and become convinced of the benefits of switching to Inbox from Gmail. Perhaps changes that only necessitate a software change require more time for subjects to develop cognitive-based inertia, whereas a software change that includes a work process change can be more quickly noticed.

Consistent with the original study, inertia only partially mediated the relationship between incumbent system constructs and the new system acceptance constructs (H4). However, we found several specific differences. Starting from the top of the detailed chart in Table 2 regarding $\mathrm{H} 4$, incumbent system habit was not fully mediated by inertia. In fact, habit did not have a significant direct effect on any of the new system acceptance constructs (see Appendix A7). The middle row in Table 2 regarding $\mathrm{H} 4$ showed the effect of transition costs on relative advantage of the new system was partially mediated by Inertia while the original study found no mediation. The effect of transition costs on intention to use the new system were partially mediated by inertia in this study whereas its effect was fully mediated in the original study. Last, the bottom row of Table 2 regarding $\mathrm{H} 4$ showed the effect of sunk costs on ease of use was partially mediated by inertia, but the original study found that its effect was fully mediated by inertia. The effect of relative advantage was not 
mediated by inertia in our replication, but it was fully mediated by inertia in the original study. As we speculated above, we believe we would have seen more consistent results if there was a larger hurdle to overcome in terms of a new work process in our context of switching e-mail systems; similar to the original study's context of switching file sharing technologies. Some of these differences might also be due to sample fluctuations.

Next, the original study found a moderating effect of inertia on the relationship between subjective norm and intentions (H8). We found a direct effect of subjective norm on intentions, but no moderation due to inertia. The original study found that inertia interacted with subjective norm to affect intentions in two situations. First, when subjective norm to switch was strong, it dominated and inertia had little effect; when the others with whom you were sharing files insisted you use Google Docs you were more likely to, even if you did not see an advantage or found it hard to use. Second, when inertia was high, subjective norm became significant; if you had strong inertia against a change, you tended to listen to the voices of others who were encouraging a switch and moderate your position a little.

We believe our different results regarding subjective norm $(\mathrm{H} 8)$ are explainable. The nature of switching in the original study was a collaborative process in which both the sender and receiver must use the same technology; one cannot use e-mail and the other Google Docs for file sharing. Thus, intentions to use are mutually bound. In that situation, subjective norm is important because it reflects a mutual decision to switch. In contrast, we studied the switch between two e-mail systems. The choice of e-mail is a personal decision. The sender can use one system for e-mail, while the receiver can use a different system. There is no mutual decision needed. Thus, it is not surprising that subjective norm played a simple straightforward role for systems solely entailing personal decisions, and a more complicated role when switching must be mutual.

Last, we comment on one difference in the control variables. Polites and Karahanna (2012) had four control variables. Two of the control variables were individual difference variables (individual propensity to resist change and PIIT) which were expected to impact one's persistence in using the incumbent system. Whereas the other control variables (self-efficacy and prior experience with the new IS) were expected to be important for one's perception of the new system. We did not find a significant effect of the control variable Propensity to Resist Change on Inertia. We speculate on why this may have occurred from both a conceptual and measurement perspective. From a conceptual perspective, our system context did not require a large enough change in both the technology used and the work processes used. This might explain why we did not see a significant effect of propensity to resist change on inertia that Polites and Karahanna (2012) observed. From a measurement perspective, none of the paths from Cognitive Rigidity, Emotional Reaction, Routine Seeking, and Short-Term Focus to comprise the formative second-order factor Propensity to Resist Change were significant. This explains the lack of the second-order factor's effect in the structural model.

\subsection{Directions for Future Research}

We draw several implications for future research. First, our replication found additional support for the status quo bias model in which inertia from incumbent systems plays a central role in influencing switching to new systems. Therefore, we believe this model is a useful addition to the research literature and encourage more research on its use. This model is also important because information systems (IS) are becoming increasingly entwined with all human activities (Leonardi, 2011), and in many cases new IS replace existing IS as opposed to a situation where there is no prior IS. Therefore the broader perspective of technology switching, which incorporates resistance to change from the existing system and acceptance of the new system, is important for IS research.

Second, we found that inertia was only influenced by sunk costs, rather than incumbent system habit and transition costs as found in the original study. We speculate that these differences are due to a change in both software and work processes in the original study, compared with a change in software only in our study (i.e., no change in work processes). Therefore, we believe more research is needed to better understand technology switching in situations where new systems do and do not require major changes to work processes.

Third, we encourage more research on the conceptualization of constructs Propensity to Resist Change, Subjective Norm, Inertia, and Habit. First, Oreg (2003) initially conceptualized Propensity to Resist change as a reflective second-order factor, whereas Polites and Karahanna (2012) modeled it as a formative second-order factor following the guidelines of Jarvis, MacKenzie, and Podsakoff (2003). Similarly, Subjective Norm (SN) has been modeled as a reflective first-order factor in other research (see Viswanath Venkatesh \& Bala, 2008), whereas Polites and Karahanna (2012) modeled it as a formative first-order factor. 
Given the importance of these constructs for technology switching and technology acceptance research, it is important that IS researchers investigate and agree on the proper modeling of these constructs as either a reflective latent variable or a formative latent variable, ideally based on theoretical reasons. In both cases (Propensity to Resist and SN), proper theoretical and modeling specification will improve the comparison of findings across studies over time and allow for improved replication and extension in the research domains of the constructs.

The conceptualization of the Inertia construct should also be revisited. Given that Polites and Karahanna (2012) and this replication did not find support of the Behavior-Based dimension as a statistically significant component of the second-order formative construct Inertia, its importance deserves further exploration. One commonality across both the original study and this replication is that the data were collected in a university setting with traditional-aged students. Perhaps the Behavior-Based dimension of Inertia is significant in samples such as professional organizations and varying age groups. Students are constantly exposed to new routines and changes in their leaning, and have to be adaptable so perhaps we should not be surprised to find Behavior-Based dimensions more flexible (i.e., less important) in their Inertia to resist switching to a new technology. We encourage future research to explore the Behavior-Based dimension with varying age groups to better understand the composition of inertia.

The conceptualization of Habit should also be revisited. Habit is theorized as a formative second-order factor with awareness, controllability, and mental efficiency as it dimensions. In both this study and the original study, awareness appears to be a suppressor variable of the other dimensions. It could be that awareness is more important than controllability and mental efficiency in specifying and modeling habit for technology switching. Specifically, we speculate that perhaps that awareness, an unconscious aspect of habit, might be more important for overcoming inertia of an incumbent system compared to controllability and mental efficiency, which we posit as more conscious aspects of habit. Upon comparison of the items used to measure these constructs, the awareness constructs seem to be measure unconscious actions (e.g., 'without being aware', 'unconsciously'), whereas controllability and mental efficiency items put the individual in more conscious control of their actions (e.g., 'overrule my impulse', 'difficult to overcome my tendency', 'deciding that I will use', 'involve much thinking', 'less mental energy'). Future research should explore the notion of a delineation between conscious and unconscious aspects of habit to better understand its influence on inertia.

Last, we found that subjective norm had a simple direct effect on intentions to use the new system, whereas the original study found a more complex two-part moderation between inertia and norms that affected intentions. We speculated that one cause of this difference is due to our study where the switching of a system was a personal choice unaffected by peers' choices to switch or not, whereas the original study examined a system that required mutual switching by the user and his/her collaboration partners. We believe this calls for more research on the switching of systems that require a mutual, coordinated decision by a set of users, rather than individual choice.

\section{Conclusion}

We conducted a methodological replication of an incumbent system's influence on the decision to switch to a new information system (i.e., technology switching) based on the work of Polites and Karahanna (2012). We found support for the notion that the use of an incumbent system can lead to the development of inertia to resist switching despite the fact that the new system might be easier to use or provide an advantage over the existing system. The efficacy of the work of Polites and Karahanna (2012) is important because information systems are becoming increasingly entwined with all human activities, and in many cases new information systems replace existing information systems as opposed to no prior system. Hence the perspective of technology switching is pertinent to IS research. While we did find support for several of the original hypotheses, our replication results had some differences which suggests an indication that there are boundary conditions of the original study that should be further explored. Specifically, the original study examined a switch that required a change in both software and work processes, whereas we studied a switch that required only a change in software (no change in work processes). Second, the original study required a mutual group decision and coordination to switch, whereas we used a system that did not require a mutual group decision. We believe the degree of change brought about a new system (e.g., software and work process vs. just software) and the individual vs. group decision about switching to a new system should be explored further in future research. 


\section{Acknowledgments}

The authors are grateful to the AIS Transactions on Replication Research editorial team for their thorough feedback on earlier versions of this paper; their comments and suggestions were of great help. In particular, thanks belongs to Editors-in-Chiefs Sue Brown, who also dedicatedly served as the Senior Editor, and Alan Dennis, two anonymous reviewers, and Managing Editor Taylor Wells.

\section{References}

Benbasat, I., \& Barki, H. (2007). Quo vadis TAM? Journal of the Association for Information Systems, 8(4), 211-218.

Cenfetelli, R. T., \& Bassellier, G. (2009). Interpretation of formative measurement in information systems research. MIS Quarterly, 689-707.

Davis, F. (1989). Perceived Usefulness Perceived ease of use and user acceptance of information technology. MIS Quarterly, 13(3), 318-340.

Davis, F., Bagozzi, R., \& Warshaw, P. (1989). User acceptance of computer technology: A comparison of two theoretical models. Management Science, 35(8), 982-1002.

Fornell, C., \& Larcker, D. (1981). Evaluating structural equation models with unobservable variables and measurement error. Journal of Marketing Research, 18(1), 39-50.

Friedman, L., \& Wall, M. (2005). Graphical views of suppression and multicollinearity in multiple linear regression. The American Statistician, 59(2), 127-136.

Hair, J. F., Hult, G. T. M., Ringle, C. M., \& Sarstedt, M. (2014). A Primer on Partial Least Squares Structural Equation Modeling (PLS-SEM). Thousand Oaks: Sage.

Jarvis, C. B., MacKenzie, S. B., \& Podsakoff, P. M. (2003). A critical review of construct indicators and measurement model misspecification in marketing and consumer research. Journal of Consumer Research, 30(2), 199-218.

Leonardi, P. M. (2011). When flexible routines meet flexible technologies: Affordance, constraint, and the imbrication of human and material agencies. MIS Quarterly, 30(1), 147-167.

Liang, H., Saraf, N., Hu, Q., \& Xue, Y. (2007). Assimilation of enterprise systems: The effect of institutional pressures and the mediating role of top management. MIS Quarterly, 31(1), 59-87.

Oreg, S. (2003). Resistance to change: Developing an individual differences measure. Journal of Applied Psychology, 88(4), 680-693.

Petter, S., Straub, D., \& Rai, A. (2007). Specifying formative constructs in information systems research. MIS Quarterly, 31(4), 623-656.

Podsakoff, P. M., MacKenzie, S. B., Lee, J. Y., \& Podsakoff, N. P. (2003). Common method biases in behavioral research: A critical review of the literature and recommended remedies. Journal of Applied Psychology, 88(5), 879-903.

Polites, G., \& Karahanna, E. (2012). Shackled to the status quo: The inhibiting effects of incumbent system habit, switching costs, and inertia on new system acceptance. MIS Quarterly, 36(1), 21-42.

Preacher, K. J., \& Hayes, A. F. (2008). Asymptotic and resampling strategies for assessing and comparing indirect effects in multiple mediator models. Behavior Research Methods, 40(3), 879-891.

Ringle, C. M., Wende, S., \& Becker, J.-M. (2015). SmartPLS 3. Boenningstedt: SmartPLS GmbH.

Straub, D., \& Burton-Jones, A. (2007). Veni Vidi Vici: Breaking the TAM Logjam. Journal of the Association for Information Systems, 8(4), 223-229.

Venkatesh, V., \& Bala, H. (2008). Technology acceptance model 3 and a research agenda on interventions. Decision Sciences, 39(2), 273-315.

Venkatesh, V., Morris, M. G., Davis, G. B., \& Davis, F. D. (2003). User acceptance of information technology: Toward a unified view. MIS Quarterly, 27(3), 425-478. 
Venkatesh, V., \& Thong, J. K. L. (2012). Consumer acceptance and use of information technology: Extending the unified theory of acceptance and use of technology. MIS Quarterly, 36(1), 157-178. 


\section{Appendix A1: Means, Construct Correlations, and Discriminant Validity for First Order Constructs}

\begin{tabular}{|l|l|l|}
\hline & $\begin{array}{l}\text { Mean } \\
\text { (St Dev) }\end{array}$ & $\begin{array}{l}\text { Composite } \\
\text { Reliability }\end{array}$ \\
\hline ABI & $4.06(1.29)$ & 0.86 \\
\hline Aware & $4.73(1.86)$ & 0.97 \\
\hline BBI & $4.7(1.35)$ & 0.91 \\
\hline CBI & $3.34(1.39)$ & 0.96 \\
\hline CTRL & $3.89(1.85)$ & 0.96 \\
\hline CogRig & $4.56(1.4)$ & 0.86 \\
\hline EFFCH & $5.35(1.54)$ & 0.94 \\
\hline EReact & $4.71(1.27)$ & 0.90 \\
\hline GDExp & $27.33(40.75)$ & 1.00 \\
\hline GDIntent & $4.47(1.54)$ & 0.97 \\
\hline GDPEOU & $5.49(1.13)$ & 0.93 \\
\hline GDRA & $4.75(1.3)$ & 0.95 \\
\hline PIIT & $4.48(1.33)$ & 0.91 \\
\hline RtSeek & $3.42(1.31)$ & 0.90 \\
\hline SE & $5.21(1.12)$ & 0.82 \\
\hline SN & $3.29(1.33)$ & $\mathrm{n} / \mathrm{a}$ \\
\hline STFocus & $3.3(1.27)$ & 0.87 \\
\hline SunkCost & $3.62(1.5)$ & 0.92 \\
\hline TranCost & $2.48(1.15)$ & 0.91 \\
\hline
\end{tabular}

\begin{tabular}{|l|l|l|l|l|l|l|l|l|l|}
\hline & ABI & Aware & BBI & CBI & CTRL & CogRig & EFFCH & EReact & GDExp \\
\hline ABI & 0.87 & & & & & & & & \\
\hline Aware & 0.10 & 0.94 & & & & & & & \\
\hline BBI & 0.64 & 0.13 & 0.92 & & & & & & \\
\hline CBI & 0.31 & 0.19 & 0.42 & 0.94 & & & & & \\
\hline CTRL & 0.03 & 0.63 & 0.11 & 0.12 & 0.93 & & & & \\
\hline CogRig & -0.01 & 0.04 & 0.11 & 0.05 & 0.13 & 0.87 & & & \\
\hline EFFCH & 0.03 & 0.61 & 0.05 & 0.04 & 0.54 & 0.04 & 0.92 & & \\
\hline EReact & 0.11 & 0.10 & 0.13 & 0.19 & 0.13 & 0.32 & 0.06 & 0.87 & \\
\hline GDExp & 0.07 & 0.03 & -0.07 & -0.08 & -0.01 & 0.09 & 0.00 & 0.00 & 1.00 \\
\hline GDIntent & -0.58 & 0.02 & -0.47 & -0.29 & 0.12 & 0.12 & 0.04 & 0.02 & 0.12 \\
\hline GDPEOU & -0.36 & -0.02 & -0.20 & -0.11 & 0.13 & 0.07 & 0.02 & -0.03 & 0.07 \\
\hline GDRA & -0.41 & 0.01 & -0.25 & 0.07 & 0.16 & 0.08 & -0.04 & 0.12 & -0.05 \\
\hline PIIT & -0.17 & 0.04 & -0.27 & -0.27 & 0.01 & 0.11 & 0.02 & -0.14 & 0.17 \\
\hline RtSeek & 0.16 & 0.01 & 0.17 & 0.28 & 0.04 & 0.22 & 0.01 & 0.43 & -0.03 \\
\hline SE & -0.23 & 0.02 & -0.19 & -0.18 & 0.03 & 0.05 & 0.10 & -0.16 & 0.13 \\
\hline SN & -0.31 & -0.04 & -0.19 & -0.04 & 0.02 & 0.17 & -0.10 & 0.04 & 0.08 \\
\hline STFocus & 0.05 & 0.01 & 0.22 & 0.23 & 0.23 & 0.22 & 0.10 & 0.38 & -0.01 \\
\hline SunkCost & 0.36 & 0.08 & 0.32 & 0.22 & 0.03 & 0.12 & -0.10 & 0.14 & 0.09 \\
\hline TranCost & 0.25 & -0.09 & 0.14 & 0.08 & -0.09 & -0.01 & 0.01 & 0.02 & -0.08 \\
\hline
\end{tabular}




\begin{tabular}{|l|l|l|l|l|l|l|l|l|l|l|}
\hline & GDIntent & GDPEOU & GDRA & PIIT & RtSeek & SE & SN & STFocus & SunkCost & TranCost \\
\hline ABI & & & & & & & & & & \\
\hline Aware & & & & & & & & & & \\
\hline BBI & & & & & & & & & & \\
\hline CBI & & & & & & & & & & \\
\hline CTRL & & & & & & & & & & \\
\hline CogRig & & & & & & & & & & \\
\hline EFFCH & & & & & & & & & & \\
\hline EReact & & & & & & & & & & \\
\hline GDExp & & & & & & & & & & \\
\hline GDIntent & 0.97 & & & & & & & & & \\
\hline GDPEOU & 0.52 & 0.93 & & & & & & & & \\
\hline GDRA & 0.54 & 0.45 & 0.93 & & & & & & & \\
\hline PIIT & 0.17 & 0.15 & 0.05 & 0.88 & & & & & & \\
\hline RtSeek & -0.10 & -0.10 & 0.09 & -0.20 & 0.91 & & & & & \\
\hline SE & 0.29 & 0.38 & 0.08 & 0.29 & -0.13 & 0.77 & & & & \\
\hline SN & 0.39 & 0.20 & 0.35 & 0.06 & 0.10 & 0.12 & $\mathrm{n} / \mathrm{a}$ & & & \\
\hline STFocus & 0.04 & 0.11 & 0.18 & -0.03 & 0.40 & -0.06 & 0.11 & 0.88 & & \\
\hline SunkCost & -0.26 & -0.19 & -0.05 & -0.07 & 0.19 & -0.14 & -0.04 & 0.12 & 0.92 & \\
\hline TranCost & -0.42 & -0.64 & -0.25 & -0.27 & 0.11 & -0.31 & -0.19 & 0.01 & 0.16 & \\
\hline
\end{tabular}




\section{Appendix A2: Cross Loadings - $1^{\text {st }}$ Order Constructs}

\begin{tabular}{|c|c|c|c|c|c|c|c|c|c|c|c|}
\hline Construct & Item & $A B I$ & Aware & BBI & CBI & CogRig & CTRL & EFFCH & EReact & GDExp & GDIntent \\
\hline \multirow{2}{*}{$A B \mid$} & $\mathrm{AB|1}$ & 0.86 & 0.08 & 0.58 & 0.35 & -0.09 & 0.00 & \begin{tabular}{|l|}
0.02 \\
\end{tabular} & $\begin{array}{ll}0.08 \\
\end{array}$ & $\begin{array}{l}0.01 \\
\end{array}$ & -0.58 \\
\hline & $\mathrm{AB|3}$ & 0.88 & 0.09 & 0.54 & 0.19 & 0.08 & 0.05 & \begin{tabular}{|l|}
0.04 \\
\end{tabular} & 0.10 & \begin{tabular}{|l|}
0.11 \\
\end{tabular} & $\begin{array}{l}-0.44 \\
\end{array}$ \\
\hline \multirow{4}{*}{ Aware } & AWARE2 & 0.08 & 0.94 & 0.12 & 0.19 & 0.00 & 0.59 & \begin{tabular}{|l|}
0.58 \\
\end{tabular} & $\begin{array}{l}0.11 \\
\end{array}$ & 0.02 & 0.03 \\
\hline & AWARE3 & 0.08 & 0.94 & 0.10 & 0.15 & 0.07 & 0.59 & \begin{tabular}{|l|}
0.63 \\
\end{tabular} & 0.10 & \begin{tabular}{|l|}
0.03 \\
\end{tabular} & 0.06 \\
\hline & AWARE4 & 0.09 & 0.95 & 0.14 & 0.19 & 0.03 & 0.56 & \begin{tabular}{|l|l|}
0.55 \\
\end{tabular} & 0.09 & 0.03 & $\begin{array}{c}-0.02 \\
\end{array}$ \\
\hline & AWARE6 & 0.12 & 0.94 & 0.14 & 0.17 & 0.07 & 0.63 & \begin{tabular}{|l|l|}
0.56 \\
\end{tabular} & $\begin{array}{ll}0.08 \\
\end{array}$ & 0.04 & -0.02 \\
\hline \multirow{2}{*}{ BBI } & BBI1 & 0.55 & 0.13 & 0.90 & 0.41 & 0.11 & 0.12 & \begin{tabular}{|l|}
0.03 \\
\end{tabular} & \begin{tabular}{|l|}
0.12 \\
\end{tabular} & \begin{tabular}{|l|l|} 
& -0.11 \\
\end{tabular} & -0.42 \\
\hline & BBI3 & 0.62 & 0.12 & 0.93 & 0.36 & 0.10 & 0.08 & \begin{tabular}{|l|l|}
0.06 \\
\end{tabular} & \begin{tabular}{|l|l}
0.13 \\
\end{tabular} & -0.03 & -0.45 \\
\hline \multirow{3}{*}{ CBI } & CBI1 & 0.30 & 0.18 & 0.42 & 0.99 & 0.04 & 0.12 & \begin{tabular}{|l|l|} 
\\
\end{tabular} & 0.19 & -0.08 & -0.28 \\
\hline & CBI2 & 0.32 & 0.19 & 0.40 & 0.89 & 0.03 & 0.12 & \begin{tabular}{|l|}
0.05 \\
\end{tabular} & 0.15 & -0.08 & -0.31 \\
\hline & CBI3 & 0.29 & 0.19 & 0.38 & 0.93 & 0.06 & 0.10 & \begin{tabular}{|l|l|}
0.04 \\
\end{tabular} & \begin{tabular}{|l|}
0.18 \\
\end{tabular} & \begin{tabular}{|l|l|} 
& -0.08 \\
\end{tabular} & -0.30 \\
\hline \multirow{2}{*}{ CogRig } & CR1 & -0.01 & 0.04 & 0.11 & 0.05 & 1.00 & 0.13 & \begin{tabular}{|l|}
0.04 \\
\end{tabular} & 0.31 & 0.09 & 0.12 \\
\hline & CR3 & 0.02 & 0.04 & 0.12 & 0.03 & 0.73 & 0.05 & \begin{tabular}{|l|}
0.01 \\
\end{tabular} & 0.30 & 0.10 & 0.05 \\
\hline \multirow{4}{*}{ CTRL } & CTRL1 & 0.05 & 0.60 & 0.13 & 0.08 & 0.12 & 0.90 & \begin{tabular}{|l|}
0.49 \\
\end{tabular} & 0.05 & 0.01 & 0.10 \\
\hline & CTRL2 & -0.02 & 0.56 & 0.08 & 0.09 & 0.12 & 0.94 & \begin{tabular}{|l|l|}
0.54 \\
\end{tabular} & 0.11 & \begin{tabular}{|l|l|}
-0.03 \\
\end{tabular} & 0.15 \\
\hline & CTRL5 & 0.02 & 0.61 & 0.10 & 0.15 & 0.13 & 0.96 & \begin{tabular}{|l|}
0.53 \\
\end{tabular} & 0.15 & \begin{tabular}{|l|l|}
-0.02 \\
\end{tabular} & 0.12 \\
\hline & CTRL7 & 0.05 & 0.59 & 0.09 & 0.11 & 0.11 & 0.94 & \begin{tabular}{|l|}
0.46 \\
\end{tabular} & 0.15 & 0.01 & 0.07 \\
\hline \multirow{3}{*}{ EFFCH } & EFFCH1 & 0.09 & 0.56 & 0.06 & 0.05 & 0.02 & 0.47 & \begin{tabular}{|l|}
0.85 \\
\end{tabular} & 0.07 & $\begin{array}{l}0.01 \\
\end{array}$ & 0.00 \\
\hline & EFFCH2 & 0.01 & 0.60 & 0.05 & 0.05 & 0.04 & 0.52 & \begin{tabular}{|l|}
0.97 \\
\end{tabular} & $\begin{array}{l}0.02 \\
\end{array}$ & 0.01 & 0.05 \\
\hline & EFFCH5 & 0.04 & 0.54 & 0.04 & 0.02 & 0.04 & 0.48 & 0.92 & 0.09 & 0.00 & 0.04 \\
\hline \multirow{3}{*}{ EReact } & ER1 & 0.19 & 0.10 & 0.24 & 0.23 & 0.29 & 0.07 & \begin{tabular}{|l|}
0.00 \\
\end{tabular} & 0.86 & -0.05 & -0.10 \\
\hline & ER2 & 0.06 & 0.06 & 0.09 & 0.14 & 0.32 & 0.16 & \begin{tabular}{|l|}
0.05 \\
\end{tabular} & $\begin{array}{ll}0.88 \\
\end{array}$ & 0.06 & 0.05 \\
\hline & ER3 & 0.02 & 0.10 & 0.02 & 0.12 & 0.25 & 0.12 & \begin{tabular}{|l|}
0.10 \\
\end{tabular} & 0.87 & 0.02 & 0.12 \\
\hline GDExp & GDExp & 0.07 & 0.03 & -0.07 & -0.08 & 0.09 & -0.01 & 0.00 & 0.00 & 1.00 & 0.12 \\
\hline \multirow{2}{*}{ GDIntent } & GDInt1 & -0.56 & 0.03 & -0.45 & -0.26 & 0.09 & 0.15 & \begin{tabular}{|l|}
0.06 \\
\end{tabular} & \begin{tabular}{|l|l|}
0.04 \\
\end{tabular} & 0.09 & 0.97 \\
\hline & GDInt2 & -0.57 & 0.00 & -0.47 & -0.31 & 0.13 & 0.08 & \begin{tabular}{|l|}
0.02 \\
\end{tabular} & 0.00 & \begin{tabular}{|l|}
0.14 \\
\end{tabular} & 0.97 \\
\hline \multirow{2}{*}{ GDPEOU } & GDPEOU1 & -0.35 & -0.01 & -0.19 & -0.12 & 0.08 & 0.16 & \begin{tabular}{|l|}
0.03 \\
\end{tabular} & 0.00 & 0.08 & 0.49 \\
\hline & GDPEOU2 & -0.32 & -0.02 & -0.19 & -0.07 & 0.05 & 0.09 & \begin{tabular}{|l|}
0.01 \\
\end{tabular} & \begin{tabular}{|l}
-0.06 \\
\end{tabular} & 0.04 & 0.47 \\
\hline \multirow{3}{*}{ GDRA } & RA1 & -0.37 & 0.04 & -0.22 & 0.08 & 0.10 & 0.19 & \begin{tabular}{|l|l|}
-0.01 \\
\end{tabular} & \begin{tabular}{|l|}
0.14 \\
\end{tabular} & -0.06 & 0.54 \\
\hline & RA2 & -0.36 & -0.02 & -0.21 & 0.09 & 0.08 & 0.12 & \begin{tabular}{|l|l|}
-0.05 \\
\end{tabular} & 0.15 & -0.05 & 0.47 \\
\hline & RA3 & -0.41 & 0.00 & -0.28 & 0.02 & 0.04 & 0.13 & \begin{tabular}{|l|l|}
-0.06 \\
\end{tabular} & 0.05 & $\begin{array}{ll}-0.03 \\
\end{array}$ & 0.50 \\
\hline \multirow{3}{*}{ PIIT } & PIIT1 & -0.18 & 0.07 & -0.25 & -0.24 & 0.13 & 0.02 & \begin{tabular}{|l|}
0.07 \\
\end{tabular} & \begin{tabular}{|l|l|}
-0.12 \\
\end{tabular} & 0.15 & 0.15 \\
\hline & PIIT2 & -0.11 & 0.03 & -0.19 & -0.22 & 0.13 & 0.05 & \begin{tabular}{|l|l|}
-0.02 \\
\end{tabular} & \begin{tabular}{|l|l|}
-0.13 \\
\end{tabular} & 0.16 & 0.13 \\
\hline & PIIT4 & -0.16 & 0.00 & -0.29 & -0.26 & 0.03 & -0.05 & \begin{tabular}{|l|}
0.00 \\
\end{tabular} & \begin{tabular}{|l|}
-0.13 \\
\end{tabular} & 0.14 & 0.16 \\
\hline \multirow{2}{*}{ RtSeek } & RS1 & 0.13 & 0.02 & 0.12 & 0.28 & 0.14 & 0.01 & \begin{tabular}{|l|l|}
-0.01 \\
\end{tabular} & $\begin{array}{l}0.43 \\
\end{array}$ & $\begin{array}{l}-0.06 \\
\end{array}$ & -0.08 \\
\hline & RS3 & 0.16 & -0.01 & 0.18 & 0.24 & 0.25 & 0.05 & \begin{tabular}{|l|}
0.02 \\
\end{tabular} & 0.35 & 0.00 & -0.09 \\
\hline \multirow{3}{*}{ SE } & SE1 & -0.21 & 0.05 & -0.24 & -0.20 & 0.07 & 0.06 & \begin{tabular}{|l|}
0.17 \\
\end{tabular} & -0.11 & 0.11 & 0.25 \\
\hline & SE2 & -0.20 & -0.03 & -0.11 & -0.11 & 0.11 & 0.02 & 0.01 & \begin{tabular}{|l|l|} 
& -0.17 \\
\end{tabular} & 0.10 & 0.20 \\
\hline & SE3 & -0.10 & 0.01 & -0.08 & -0.11 & -0.09 & -0.01 & \begin{tabular}{|l|l|}
0.05 \\
\end{tabular} & \begin{tabular}{|l|l|}
-0.10 \\
\end{tabular} & 0.09 & 0.21 \\
\hline \multirow{3}{*}{ SN } & GDSF1 & -0.28 & -0.03 & -0.18 & -0.03 & 0.17 & 0.02 & \begin{tabular}{|l|l|}
-0.10 \\
\end{tabular} & 0.06 & 0.08 & 0.38 \\
\hline & GDSF3 & -0.32 & -0.04 & -0.19 & -0.04 & 0.17 & 0.02 & \begin{tabular}{|l|l|}
-0.09 \\
\end{tabular} & 0.03 & 0.07 & 0.38 \\
\hline & GDSF5 & $\begin{array}{c}-0.27 \\
\end{array}$ & $\begin{array}{l}-0.04 \\
\end{array}$ & -0.12 & -0.03 & 0.18 & 0.02 & \begin{tabular}{|l|l|}
-0.09 \\
\end{tabular} & 0.03 & 0.04 & 0.33 \\
\hline \multirow{2}{*}{ STFocus } & STF3 & 0.08 & 0.00 & 0.26 & 0.23 & 0.23 & 0.19 & \begin{tabular}{|l|}
0.06 \\
\end{tabular} & 0.38 & 0.01 & 0.04 \\
\hline & STF4 & 0.01 & 0.01 & 0.13 & 0.18 & 0.16 & 0.22 & \begin{tabular}{|l|}
0.12 \\
\end{tabular} & 0.29 & $\begin{array}{ll}-0.02 \\
\end{array}$ & 0.03 \\
\hline \multirow{2}{*}{ SunkCost } & SnkCost1 & 0.34 & 0.02 & 0.25 & 0.20 & 0.09 & 0.02 & \begin{tabular}{|l|l|}
-0.12 \\
\end{tabular} & 0.16 & 0.09 & -0.21 \\
\hline & SnkCost2 & 0.33 & 0.11 & 0.32 & 0.21 & 0.12 & 0.03 & \begin{tabular}{|l|l|}
-0.08 \\
\end{tabular} & $\begin{array}{l}0.12 \\
\end{array}$ & 0.08 & $\begin{array}{c}-0.27 \\
\end{array}$ \\
\hline \multirow{2}{*}{ TranCost } & TrnCost1 & 0.24 & -0.11 & 0.11 & 0.01 & -0.01 & -0.11 & \begin{tabular}{|l|}
0.02 \\
\end{tabular} & \begin{tabular}{|l|}
-0.01 \\
\end{tabular} & -0.05 & -0.36 \\
\hline & TrnCost2 & 0.21 & -0.07 & 0.14 & 0.13 & 0.00 & -0.06 & \begin{tabular}{|l|l|}
-0.01 \\
\end{tabular} & $\begin{array}{ll}0.04 \\
\end{array}$ & -0.10 & $\begin{array}{l}-0.42 \\
\end{array}$ \\
\hline
\end{tabular}




\begin{tabular}{|c|c|c|c|c|c|c|c|c|c|c|}
\hline Construct & Item & GDPEOU & GDRA & PIIT & RtSeek & SE & SN & STFocus & SunkCost & TranCos \\
\hline \multirow[b]{2}{*}{$A B I$} & ABI1 & -0.36 & -0.35 & -0.19 & 0.12 & -0.25 & -0.26 & $\begin{array}{l}0.04 \\
\end{array}$ & 0.35 & 0.28 \\
\hline & ABI3 & -0.27 & -0.36 & -0.11 & 0.17 & -0.15 & -0.28 & 0.04 & 0.28 & 0.16 \\
\hline \multirow{4}{*}{ Aware } & AWARE2 & 0.00 & 0.03 & 0.02 & 0.04 & -0.01 & -0.04 & 0.03 & 0.08 & -0.06 \\
\hline & AWARE3 & 0.01 & -0.01 & 0.04 & -0.01 & 0.06 & -0.04 & 0.03 & 0.05 & -0.11 \\
\hline & AWARE4 & -0.07 & -0.01 & 0.03 & 0.00 & 0.00 & -0.05 & \begin{tabular}{|l|}
-0.02 \\
\end{tabular} & 0.08 & -0.07 \\
\hline & AWARE6 & -0.01 & 0.03 & 0.06 & -0.01 & 0.02 & -0.01 & \begin{tabular}{|l|}
-0.02 \\
\end{tabular} & 0.09 & -0.11 \\
\hline \multirow{2}{*}{$\mathrm{BBI}$} & BBI1 & $\begin{array}{l}-0.17 \\
\end{array}$ & -0.19 & -0.27 & 0.16 & -0.21 & \begin{tabular}{|l|}
-0.09 \\
\end{tabular} & 0.21 & 0.26 & 0.15 \\
\hline & BBI3 & -0.20 & -0.27 & $\begin{array}{l}-0.23 \\
\end{array}$ & 0.15 & -0.14 & -0.24 & 0.19 & 0.32 & 0.10 \\
\hline \multirow{3}{*}{ CBI } & CBI1 & -0.10 & 0.08 & -0.27 & 0.28 & -0.18 & \begin{tabular}{|l|}
-0.04 \\
\end{tabular} & 0.22 & 0.21 & 0.08 \\
\hline & CBI2 & -0.17 & 0.00 & -0.25 & 0.24 & -0.18 & -0.05 & 0.22 & 0.27 & 0.10 \\
\hline & CBI3 & -0.12 & 0.03 & -0.25 & 0.26 & $\begin{array}{l}-0.17 \\
\end{array}$ & -0.03 & \begin{tabular}{|l|}
0.22 \\
\end{tabular} & 0.23 & 0.05 \\
\hline \multirow{2}{*}{ CogRig } & CR1 & 0.08 & 0.09 & 0.11 & 0.22 & 0.05 & 0.18 & 0.22 & 0.12 & -0.01 \\
\hline & CR3 & -0.02 & -0.06 & 0.13 & 0.16 & 0.02 & 0.09 & 0.16 & 0.07 & 0.01 \\
\hline \multirow{4}{*}{ CTRL } & CTRL1 & 0.11 & 0.09 & -0.03 & -0.02 & 0.00 & 0.04 & 0.19 & -0.02 & -0.12 \\
\hline & CTRL2 & 0.15 & 0.15 & 0.04 & 0.02 & 0.08 & 0.00 & 0.18 & -0.01 & -0.10 \\
\hline & CTRL5 & 0.14 & 0.18 & 0.02 & 0.04 & 0.06 & 0.03 & 0.24 & 0.04 & -0.09 \\
\hline & CTRL 7 & 0.10 & 0.15 & 0.00 & 0.09 & -0.02 & $\begin{array}{l}0.01 \\
\end{array}$ & 0.23 & 0.08 & -0.04 \\
\hline \multirow{3}{*}{ EFFCH } & EFFCH1 & 0.01 & -0.06 & -0.01 & 0.02 & 0.05 & -0.08 & \begin{tabular}{|l|l|} 
\\
\end{tabular} & -0.01 & 0.02 \\
\hline & EFFCH2 & 0.04 & -0.02 & 0.01 & -0.01 & 0.09 & -0.08 & \begin{tabular}{|l|}
0.12 \\
\end{tabular} & -0.13 & -0.01 \\
\hline & EFFCH5 & -0.01 & -0.06 & 0.04 & 0.02 & 0.14 & \begin{tabular}{|l|}
-0.11 \\
\end{tabular} & 0.08 & -0.08 & 0.02 \\
\hline \multirow{3}{*}{ EReact } & ER1 & -0.12 & 0.06 & -0.13 & 0.34 & -0.16 & 0.00 & 0.34 & 0.15 & 0.06 \\
\hline & ER2 & 0.03 & 0.11 & -0.13 & 0.41 & -0.13 & 0.07 & 0.35 & 0.16 & -0.01 \\
\hline & ER3 & 0.03 & 0.15 & -0.12 & 0.38 & -0.13 & 0.04 & 0.30 & 0.08 & -0.02 \\
\hline GDExp & GDEx[ & 0.07 & -0.05 & 0.17 & -0.03 & 0.13 & \begin{tabular}{|l|}
0.08 \\
\end{tabular} & \begin{tabular}{|l|}
-0.01 \\
\end{tabular} & 0.09 & -0.08 \\
\hline \multirow{2}{*}{ GDIntent } & GDInt11 & 0.53 & 0.57 & 0.14 & -0.07 & 0.27 & 0.37 & 0.07 & -0.24 & $\begin{array}{l}-0.42 \\
\end{array}$ \\
\hline & GDInt2 & 0.48 & 0.48 & 0.18 & $\begin{array}{l}-0.12 \\
\end{array}$ & 0.29 & \begin{tabular}{|l|}
0.39 \\
\end{tabular} & 0.00 & -0.27 & -0.40 \\
\hline \multirow{2}{*}{ GDPEOU } & GDPEOU1 & 0.93 & 0.42 & 0.13 & -0.07 & 0.34 & 0.19 & 0.10 & -0.20 & -0.60 \\
\hline & GDPEOU2 & 0.93 & 0.41 & 0.16 & -0.11 & 0.36 & 0.18 & 0.10 & -0.15 & -0.59 \\
\hline \multirow{3}{*}{ GDRA } & RA1 & 0.47 & 0.93 & 0.02 & 0.08 & 0.06 & 0.32 & 0.21 & -0.06 & -0.30 \\
\hline & RA2 & 0.41 & 0.95 & 0.07 & 0.11 & 0.06 & 0.35 & 0.23 & -0.05 & -0.21 \\
\hline & RA3 & 0.38 & 0.92 & 0.04 & 0.07 & 0.11 & 0.33 & 0.07 & -0.04 & -0.19 \\
\hline \multirow{3}{*}{ PIIT } & PIIT1 & 0.13 & 0.05 & 0.88 & -0.20 & 0.27 & 0.01 & -0.09 & -0.08 & -0.22 \\
\hline & PIIT2 & 0.15 & 0.08 & 0.86 & -0.16 & 0.23 & 0.08 & 0.09 & -0.05 & -0.25 \\
\hline & PIIT4 & 0.13 & -0.01 & 0.90 & -0.17 & 0.28 & 0.07 & -0.09 & -0.05 & -0.25 \\
\hline \multirow[b]{2}{*}{ RtSeek } & RS1 & -0.13 & 0.10 & -0.16 & 0.88 & -0.12 & 0.05 & 0.32 & 0.18 & 0.09 \\
\hline & RS3 & -0.05 & 0.07 & -0.20 & 0.93 & -0.13 & 0.12 & 0.39 & 0.17 & 0.11 \\
\hline \multirow{3}{*}{ SE } & SE1 & 0.30 & 0.08 & 0.21 & -0.11 & 0.79 & 0.15 & \begin{tabular}{|l|}
-0.01 \\
\end{tabular} & -0.18 & -0.21 \\
\hline & SE2 & 0.33 & 0.04 & 0.23 & -0.10 & 0.78 & 0.12 & -0.04 & -0.09 & -0.28 \\
\hline & SE3 & 0.24 & 0.07 & 0.24 & -0.10 & 0.75 & -0.01 & -0.10 & -0.06 & -0.24 \\
\hline \multirow{3}{*}{ SN } & GDSF1 & 0.21 & 0.37 & 0.07 & 0.13 & 0.13 & 0.98 & 0.12 & -0.03 & -0.19 \\
\hline & GDSF3 & 0.19 & 0.34 & 0.05 & 0.08 & 0.11 & 0.99 & 0.10 & -0.05 & -0.19 \\
\hline & GDSF5 & 0.17 & 0.27 & 0.03 & 0.06 & 0.13 & 0.86 & 0.06 & 0.00 & -0.16 \\
\hline \multirow[b]{2}{*}{ STFocus } & STF3 & 0.14 & 0.15 & -0.02 & 0.35 & -0.02 & 0.07 & 0.86 & 0.13 & -0.01 \\
\hline & STF4 & 0.05 & 0.17 & -0.03 & 0.35 & -0.09 & 0.11 & 0.90 & 0.09 & 0.03 \\
\hline \multirow{2}{*}{ SunkCost } & SnkCost1 & -0.12 & -0.03 & -0.08 & 0.20 & -0.14 & $\begin{array}{ll}-0.02 \\
\end{array}$ & 0.20 & 0.87 & 0.13 \\
\hline & SnkCost2 & -0.21 & -0.06 & -0.06 & 0.17 & -0.13 & -0.05 & 0.07 & 0.96 & 0.16 \\
\hline \multirow[b]{2}{*}{ TranCost } & TrnCost1 & -0.58 & -0.24 & -0.18 & 0.07 & -0.27 & -0.16 & \begin{tabular}{|l|}
-0.02 \\
\end{tabular} & 0.15 & 0.92 \\
\hline & TrnCost2 & -0.60 & -0.22 & -0.32 & 0.13 & -0.31 & -0.19 & 0.05 & 0.14 & 0.91 \\
\hline
\end{tabular}




\section{Appendix A3: Weights for Aggregate and Formative Constructs}

\begin{tabular}{|c|c|c|}
\hline Construct & Dimension/Item & Weight \\
\hline Habit & Summated Scale & $1.00^{\star \star \star}$ \\
\hline \multirow[t]{3}{*}{ Inertia } & $\mathrm{ABI}$ & $0.87^{* * *}$ \\
\hline & $\mathrm{BBI}$ & 0.16 (n.s.) \\
\hline & $\mathrm{CBI}$ & 0.07 (n.s.) \\
\hline \multirow{4}{*}{$\begin{array}{l}\text { Propensity } \\
\text { to Resist } \\
\text { Change }\end{array}$} & Cognitive Rigidity & -0.54 (n.s.) \\
\hline & Emotional Reaction & 0.16 (n.s.) \\
\hline & Routine Seeking & 0.93 (n.s.) \\
\hline & Short-Term Focus & -0.58 (n.s.) \\
\hline $\begin{array}{l}\text { Subjective } \\
\text { Norm }\end{array}$ & Summated Scale & $1.00^{\star \star \star}$ \\
\hline
\end{tabular}

Note: ${ }^{*} p<.05,{ }^{\star \star} p<0.01,{ }^{* \star \star} p<0.001$ 


\section{Appendix A4: Inter-Construct Correlations for PLS Model with Second Order Constructs}

\begin{tabular}{|l|l|l|l|l|l|l|l|}
\hline & GDExp & GDIntent & GDPEOU & GDRA & HABIT & INERTIA & I*SN \\
\hline GDExp & 1.00 & & & & & & \\
\hline GDIntent & 0.12 & 0.97 & & & & & \\
\hline GDPEOU & 0.07 & 0.52 & 0.93 & & & & \\
\hline GDRA & -0.05 & 0.54 & 0.45 & 0.93 & & & \\
\hline HABIT & 0.01 & 0.07 & 0.05 & 0.06 & 1.00 & & \\
\hline INERTIA & 0.04 & -0.60 & -0.35 & -0.39 & 0.08 & $n / a$ & \\
\hline I*SN & 0.05 & 0.17 & 0.12 & 0.02 & -0.10 & -0.13 & 1.00 \\
\hline PIIT & 0.17 & 0.17 & 0.15 & 0.04 & 0.03 & -0.21 & 0.02 \\
\hline RESIST & -0.07 & -0.17 & -0.20 & -0.04 & -0.08 & 0.13 & -0.10 \\
\hline SE & 0.13 & 0.29 & 0.38 & 0.08 & 0.06 & -0.24 & 0.06 \\
\hline SN & 0.07 & 0.38 & 0.20 & 0.34 & -0.04 & -0.29 & 0.06 \\
\hline SunkCost & 0.09 & -0.26 & -0.18 & -0.05 & 0.00 & 0.38 & -0.12 \\
\hline TranCost & -0.08 & -0.42 & -0.64 & -0.25 & -0.07 & 0.24 & 0.00 \\
\hline
\end{tabular}

\begin{tabular}{|l|l|l|l|l|l|l|}
\hline & PIIT & RESIST & SE & SN & SunkCost & TranCost \\
\hline GDExp & & & & & & \\
\hline GDIntent & & & & & & \\
\hline GDPEOU & & & & & & \\
\hline GDRA & & & & & & \\
\hline HABIT & & & & & & \\
\hline INERTIA & & & & & & \\
\hline I*SN & & & & & & \\
\hline PIIT & 0.88 & & & & & \\
\hline RESIST & -0.25 & n/a & & & & \\
\hline SE & 0.30 & -0.14 & 0.77 & & & \\
\hline SN & 0.05 & -0.06 & 0.13 & 1.00 & & \\
\hline SunkCost & -0.07 & 0.06 & -0.15 & -0.02 & 0.93 & \\
\hline TranCost & -0.27 & 0.10 & -0.31 & -0.19 & 0.16 & 0.92 \\
\hline
\end{tabular}




\section{Appendix A5: Model Constructs and Measures}

\begin{tabular}{|c|c|c|}
\hline Construct & Item & Item Wording \\
\hline \multirow{4}{*}{$\begin{array}{l}\text { Habit - } \\
\text { Awareness } \\
\text { (Polites } \\
2009)\end{array}$} & AWARE2 & $\begin{array}{l}\text { Whenever I need to check/send e-mails, I choose to use Gmail without even being } \\
\text { aware of (making) the choice. }\end{array}$ \\
\hline & AWARE3 & Whenever I need to check/send e-mails, I unconsciously start using Gmail. \\
\hline & AWARE4 & Choosing Gmail when I want check/send e-mails is something I do without being \\
\hline & AWARE6 & Choosing Gmail to check/send e-mails is something I do unconsciously. \\
\hline \multirow{4}{*}{$\begin{array}{l}\text { Habit - } \\
\text { Controllability } \\
\text { (Polites } \\
\text { 2009) }\end{array}$} & CTRL1 & I (would) find it difficult to overrule my impulse to use Gmail to check/send e-mails. \\
\hline & CTRL2 & I (would) find it difficult to overcome my tendency to use Gmail to check/send e- \\
\hline & CTRL5 & It would be difficult to control my tendency to use Gmail to check/send e-mails. \\
\hline & CTRL7 & It is [would be] hard to restrain my urge to use Gmail to check/send e-mails. \\
\hline \multirow{3}{*}{$\begin{array}{l}\text { Habit - } \\
\text { Mental } \\
\text { Efficiency } \\
\text { (Polites } \\
2009 \text { ) }\end{array}$} & EFFCH1 & $\begin{array}{l}\text { I do not need to devote a lot of mental effort to deciding that I will use Gmail to } \\
\text { check/send e-mails. }\end{array}$ \\
\hline & EFFCH2 & Selecting Gmail to check/send e-mails does not involve much thinking. \\
\hline & EFFCH5 & Choosing Gmail to check/send e-mails requires less mental energy. \\
\hline \multirow{2}{*}{$\begin{array}{l}\text { Indiv Diff - } \\
\text { Cognitive } \\
\text { Rigidity } \\
\text { (Oreg 2003) }\end{array}$} & CR1 & Once I've come to a conclusion, I'm not likely to change my mind. \\
\hline & CR3 & I don't change my mind easily. \\
\hline \multirow{3}{*}{$\begin{array}{l}\text { Indiv Diff - } \\
\text { Emotional } \\
\text { Reaction } \\
\text { (Oreg 2003) }\end{array}$} & ER1 & $\begin{array}{l}\text { If I were to be informed that there's going to be a significant change regarding the } \\
\text { way things are done in my classes, I would probably feel stressed. }\end{array}$ \\
\hline & ER2 & When I am informed of a change of plans, I tense up a bit. \\
\hline & ER3 & When things don't go according to plans, it stresses me out. \\
\hline \multirow{2}{*}{$\begin{array}{l}\text { Indiv Diff - } \\
\text { Routine } \\
\text { Seeking } \\
\text { (Oreg 2003) }\end{array}$} & RS1 & I generally consider changes to be a negative thing. \\
\hline & RS3 & I like to do the same old things rather than try new and different ones. \\
\hline \multirow{2}{*}{$\begin{array}{l}\text { Indiv Diff - } \\
\text { Short -Term } \\
\text { Focus (Oreg } \\
\text { 2003) }\end{array}$} & STF3 & $\begin{array}{l}\text { When someone pressures me to change something, I tend to resist it even if I think } \\
\text { the change may ultimately benefit me. }\end{array}$ \\
\hline & STF4 & I sometimes find myself avoiding changes that I know will be good for me. \\
\hline \multirow{3}{*}{$\begin{array}{l}\text { Indiv Diff - } \\
\text { PIIT } \\
\text { (Agarwal and } \\
\text { Prasad 1998) }\end{array}$} & PIIT1 & $\begin{array}{l}\text { If I heard about a new information technology, I would look for ways to experiment } \\
\text { with it. }\end{array}$ \\
\hline & PIIT2 & Among my peers, I am usually the first to try out new information technologies. \\
\hline & PIIT4 & I like to experiment with new information technologies. \\
\hline \multirow{3}{*}{$\begin{array}{l}\text { Inertia - } \\
\text { Affective } \\
\text { Based }\end{array}$} & \multicolumn{2}{|c|}{ I [will] continue using my existing method for checking/sending e-mails... } \\
\hline & $\mathrm{ABI1}$ & ...because it would be stressful to change. \\
\hline & $\mathrm{ABI3}$ & because I enjoy doing so. \\
\hline \multirow{3}{*}{$\begin{array}{l}\text { Inertia - } \\
\text { Behavioral } \\
\text { Based }\end{array}$} & \multicolumn{2}{|c|}{ I [will] continue using my existing method for checking/sending e-mails.. } \\
\hline & BBI1 & ...simply because it is what I have always done. \\
\hline & $\mathrm{BBI} 3$ & ...simply because l've done so regularly in the past. \\
\hline
\end{tabular}




\begin{tabular}{|c|c|c|}
\hline Construct & Item & Item Wording \\
\hline \multirow{4}{*}{$\begin{array}{l}\text { Inertia - } \\
\text { Cognitive } \\
\text { Based }\end{array}$} & \multicolumn{2}{|c|}{ I [will] continue using my existing method for checking/sending e-mails... } \\
\hline & CBI1 & even though I know it is not the best way of doing things. \\
\hline & $\mathrm{CBI} 2$ & even though I know it is not the most efficient way of doing things. \\
\hline & $\mathrm{CBI3}$ & ...even though I know it is not the most effective way to do things. \\
\hline \multirow{2}{*}{$\begin{array}{l}\text { Transition } \\
\text { Costs } \\
\text { (Moore } \\
2000 \text { ) }\end{array}$} & TrnCost1 & $\begin{array}{l}\text { Learning how to use Inbox to check/send e-mails would not take much time. } \\
\text { [reverse coded item] }\end{array}$ \\
\hline & TrnCost2 & $\begin{array}{l}\text { Becoming skillful at using Inbox to check/send e-mails would be easy for me. } \\
\text { [reverse coded item] }\end{array}$ \\
\hline \multirow{2}{*}{$\begin{array}{l}\text { Sunk Costs } \\
\text { (Moore } \\
2000 \text { ) }\end{array}$} & SnkCost1 & $\begin{array}{l}\text { I have already invested a lot of time in learning to use my current method for } \\
\text { checking/sending e-mails. }\end{array}$ \\
\hline & SnkCost2 & $\begin{array}{l}\text { I have already invested a lot of time in perfecting my skills at using my current } \\
\text { method for checking/sending e-mails. }\end{array}$ \\
\hline \multirow{2}{*}{$\begin{array}{l}\text { Perceived } \\
\text { Ease of Use } \\
\text { (Karahanna } \\
\text { et al. 2006; } \\
\text { Venkatesh } \\
\text { 2003) }\end{array}$} & GDPEOU1 & I would find Inbox easy to use for checking/sending e-mails. \\
\hline & GDPEOU2 & Using Inbox to check/send e-mails would be clear and understandable. \\
\hline \multirow{3}{*}{$\begin{array}{l}\text { Relative } \\
\text { Advantage } \\
\text { (Karahanna } \\
\text { et al. 2006; } \\
\text { Venkatesh } \\
\text { 2003) }\end{array}$} & RA1 & $\begin{array}{l}\text { Using Inbox to check/send e-mails, rather than my current method of } \\
\text { checking/sending e-mails, would enhance my effectiveness. }\end{array}$ \\
\hline & RA2 & $\begin{array}{l}\text { Using Inbox app to check/send e-mails, rather than my current method of } \\
\text { checking/sending would e-mails, would increase my productivity. }\end{array}$ \\
\hline & RA3 & $\begin{array}{l}\text { Using Inbox app to check/send e-mails, rather than my current method of } \\
\text { checking/sending e-mails, would increase my performance. }\end{array}$ \\
\hline \multirow{3}{*}{$\begin{array}{l}\text { Subjective } \\
\text { Norm } \\
\text { (formative) } \\
\text { (Venkatesh } \\
\text { et al. 2003) }\end{array}$} & GDSF1 & My friends think I should use Inbox to check/send e-mails. \\
\hline & GDSF3 & My teammates think I should use Inbox to check/send e-mails. \\
\hline & GDSF5 & My professors think I should use Inbox to check/send e-mails. \\
\hline \multirow{3}{*}{$\begin{array}{l}\text { Inner Self- } \\
\text { Efficacy } \\
\text { (Thatcher et } \\
\text { al. 2008) }\end{array}$} & SE1 & $\begin{array}{l}\text { I could use Inbox to check/send e-mails if there was no one around to tell me what } \\
\text { to do. }\end{array}$ \\
\hline & SE2 & I could use Inbox to check/send e-mails if I had never used a system like it before. \\
\hline & SE3 & I could use Inbox to check/send e-mails if I had only the online help for reference. \\
\hline \multirow{2}{*}{$\begin{array}{l}\text { New System } \\
\text { Usage } \\
\text { Intention } \\
\text { (Thatcher et } \\
\text { al. 2008) }\end{array}$} & GDInt1 & I intend to use Inbox to check/send e-mails in the future. \\
\hline & GDInt2 & I plan to use Inbox to check/send e-mails in the future. \\
\hline $\begin{array}{l}\text { Experience } \\
\text { with Google } \\
\text { Gmail }\end{array}$ & GDExp & $\begin{array}{l}\text { Please indicate how much experience, in months, you currently have using Inbox. } \\
\text { (If you have never used Inbox before, please enter "0".) }\end{array}$ \\
\hline
\end{tabular}




\section{Appendix A6: Total Effects (Listed in Decreasing Order by Size)}

\begin{tabular}{|c|c|c|}
\hline Dependent Variable & Independent Variable & Total Effect \\
\hline \multirow{12}{*}{ Intention } & GDPEOU & $0.31^{* * *}$ \\
\hline & GDRA & $0.26^{* * *}$ \\
\hline & SE & $0.19^{*}$ \\
\hline & SN & $0.12^{*}$ \\
\hline & GDExp & 0.08 \\
\hline & TranCost & -0.07 \\
\hline & Intertia*SN & 0.06 \\
\hline & PIIT & 0.04 \\
\hline & Habit & -0.06 \\
\hline & Resist & -0.10 \\
\hline & SunkCost & $-0.17^{\star \star \star}$ \\
\hline & Inertia & $-0.52^{\star * *}$ \\
\hline \multirow{8}{*}{$\begin{array}{l}\text { Perceived Ease of } \\
\text { Use }\end{array}$} & SE & $0.33^{* \star *}$ \\
\hline & TranCost & -0.03 \\
\hline & GDExp & 0.02 \\
\hline & PIIT & 0.00 \\
\hline & Habit & -0.03 \\
\hline & SunkCost & $-0.09^{\star *}$ \\
\hline & Resist & -0.14 \\
\hline & Inertia & $-0.27^{* \star *}$ \\
\hline \multirow{9}{*}{ Relative Advantage } & GDPEOU & $0.41^{* * *}$ \\
\hline & SE & 0.05 \\
\hline & TranCost & -0.05 \\
\hline & PIIT & 0.01 \\
\hline & Resist & -0.03 \\
\hline & Habit & -0.04 \\
\hline & GDExp & -0.06 \\
\hline & SunkCost & $-0.13^{* * *}$ \\
\hline & Inertia & $-0.39^{\star * *}$ \\
\hline \multirow{7}{*}{ Inertia } & SunkCost & $0.32^{\star \star *}$ \\
\hline & Habit & 0.11 \\
\hline & Resist & 0.07 \\
\hline & GDExp & 0.06 \\
\hline & PIIT & -0.11 \\
\hline & SE & -0.13 \\
\hline & TranCost & 0.13 \\
\hline
\end{tabular}

Note: ${ }^{*} p<0.05 \quad{ }^{* *} p<0.01{ }^{* * *} p<0.001$ 


\section{Appendix A7: Mediation Test Results}

\begin{tabular}{|c|c|c|c|c|}
\hline \multirow[b]{2}{*}{ Mediation Tested } & \multicolumn{2}{|c|}{ Step 1 - Direct Effect without mediator } & \multicolumn{2}{|l|}{ Step 2 - Indirect Effect } \\
\hline & Path & Beta & Path & Beta \\
\hline H --> I --> PEOU & $\mathrm{H}$--> PEOU & 0.06 & H --> | --> PEOU & $x$ \\
\hline$H$--> I --> RA & $H-->R A$ & 0.07 & $H-->\mid->$ RA & $\mathrm{x}$ \\
\hline H --> | --> GDIntent & H --> GDIntent & 0.08 & $H$--> I --> GDIntent & $x$ \\
\hline SC --> I --> PEOU & SC --> PEOU & $-0.20^{* *}$ & SC --> I --> PEOU & $-0.13^{* *}$ \\
\hline$S C$--> | --> RA & SC --> RA & -0.06 & SC --> | --> RA & $x$ \\
\hline SC --> | --> GDIntent & SC --> GDIntent & $-0.26^{* * *}$ & SC --> I --> GDIntent & $-0.23^{* * *}$ \\
\hline TC --> I --> PEOU & TC --> PEOU & $-0.64^{* * *}$ & TC --> | --> PEOU & $-0.05^{*}$ \\
\hline TC --> I --> RA & TC --> RA & $-0.26^{* *}$ & TC --> I --> RA & $-0.10^{*}$ \\
\hline TC --> | --> GDIntent & TC --> GDIntent & $-0.42^{* * *}$ & TC --> I --> GDIntent & $-0.13^{* *}$ \\
\hline PEOU --> RA --> GDIntent & PEOU --> GDIntent & $0.52^{\star \star *}$ & PEOU --> RA --> GDIntent & $0.17^{* * *}$ \\
\hline I --> SN --> GDIntent & | --> GDIntent & $-0.60^{* * *}$ & I --> SN --> GDIntent & $-0.07^{*}$ \\
\hline
\end{tabular}

Note: ${ }^{*} p<0.05{ }^{* *} p<0.01{ }^{* * *} p<0.001$

\begin{tabular}{|c|c|c|c|c|}
\hline \multirow[b]{2}{*}{ Mediation Tested } & \multicolumn{3}{|c|}{ Step 3 - Indirect VAF } & \multirow[b]{2}{*}{$\begin{array}{l}\text { Mediation } \\
\text { Result }\end{array}$} \\
\hline & Path & $\begin{array}{l}\text { Beta with } \\
\text { mediator }\end{array}$ & $\begin{array}{l}\text { Indirect } \\
\text { VAF (\%) }\end{array}$ & \\
\hline $\mathrm{H}$--> | --> PEOU & $\mathrm{H}$--> PEOU & $x$ & $x$ & No mediation \\
\hline$H$--> I --> RA & $\mathrm{H}-->\mathrm{RA}$ & $\mathrm{x}$ & $x$ & No mediation \\
\hline$H$--> I --> GDIntent & H --> GDIntent & $x$ & $x$ & No mediation \\
\hline SC -->I --> PEOU & SC --> PEOU & -0.06 & 69.06 & Partial mediation \\
\hline$S C-->\mid-->R A$ & SC --> RA & $\mathrm{x}$ & $x$ & No mediation \\
\hline SC --> I --> GDIntent & SC --> GDIntent & -0.03 & 87.26 & Full mediation \\
\hline TC --> I --> PEOU & TC --> PEOU & -0.59 & 8.44 & No mediation \\
\hline TC --> | --> RA & TC --> RA & -0.15 & 38.87 & Partial mediation \\
\hline TC --> I --> GDIntent & TC --> GDIntent & -0.30 & 29.78 & Partial mediation \\
\hline PEOU --> RA --> GDIntent & PEOU --> GDIntent & 0.35 & 33.20 & Partial mediation \\
\hline | --> SN --> GDIntent & I --> GDIntent & -0.53 & 11.03 & No mediation \\
\hline
\end{tabular}




\section{Appendix A8: Task Instructions}

Google Inbox was launched on October $22^{\text {nd }}, 2014$ as invitation only beta. The product is now available for everyone. The rationale behind this product which drastically different than Gmail, is that we all are receiving more e-mails than ever and how can we identify the most important ones without having to scroll through 100s of e-mails. In the deluge of information flooding our inboxes, it's quite difficult to identify the most relevant information. Inbox offers several features such as bundles which groups together all you travel information, highlights such as upcoming bill payments and remainders for upcoming events.

To take a quick tour of Google Inbox, and get detailed information on capabilities of Google Inbox, please follow the steps bellow.

1. Step 1, watch the video at: https://goo.gl//PuFCo

2. Go to the following website, by opening a NEW BROWSER WINDOW:

https://www.Google.com/inbox/

3. Review the website to get additional information about Inbox and once you have explored all the features offered by Google Inbox, you can login the inbox app by clicking Sign In or Go to

Inbox buttons on the top right corner. (You can use your personal Gmail account or your university Umail account to sign in)

4. Perform the following activities:-

a. Click on compose e-mail button (the red colored + sign in bottom right hand side), and sent a test e-mail. You can use your own e-mail address as the recipient.

b. Create a reminder using the mail button).

c. Explore the various categories that Inbox automatically created to group your mails such as Purchases, Promotions, Updates, and Social etc.

5. Goto the survey using the following URL: (You may find it convenient to leave the Google Inbox browser window open until you complete the survey)

a. $\leq U R L$ for survey $\|>$ 


\section{About the Authors}

Binny M. Samuel. is an Assistant Professor at the University of Cincinnati. He earned his Ph.D. from the Kelley School of Business at Indiana University. He also holds a Bachelor of Science in Business and M.B.A, both with emphasis in Accounting and Information Systems. Prior to his doctoral education, he worked in IT roles at Ford Motor Company and at Indiana University. His current research interests focus on human factor issues in order to 1) improve the ways in which the information processing needs of an organization are analyzed, designed, and maintained and 2) understand how cognition and emotions affect an individual's decision to adopt and ultimately use systems. His work can be found in Journal of Information Technology, IEEE Transactions on Software Engineering, and MIS Quarterly among others.

George K. Joy is a Consultant aligned with the SAP Finance practice at Deloitte Consulting. He earned his Master's degree in Information Systems from the Kelley School of Business at Indiana University focusing on Business Intelligence. His research interests include data driven business decision-making, technology driven behavioral change and use of Machine Learning to improve business process efficiency. Prior to his Master's, he worked at SAP Labs as a Quality Associate within the platform team. As a Technology Consultant, he has worked on transformation initiatives to improve reporting and analytical capabilities of Business Units. He holds a Bachelor's Degree in Computer Science.

Copyright ( 2018 by the Association for Information Systems. Permission to make digital or hard copies of all or part of this work for personal or classroom use is granted without fee provided that copies are not made or distributed for profit or commercial advantage and that copies bear this notice and full citation on the first page. Copyright for components of this work owned by others than the Association for Information Systems must be honored. Abstracting with credit is permitted. To copy otherwise, to republish, to post on servers, or to redistribute to lists requires prior specific permission and/or fee. Request permission to publish from: AIS Administrative Office, P.O. Box 2712 Atlanta, GA, 30301-2712 Attn: Reprints or via e-mail from ais@aisnet.org. 